\title{
Development of an $\omega$-Phase in Grade 2 Titanium Processed by HPT at High Hydrostatic Pressure
}

\author{
Roberto B. Figueiredo ${ }^{a *}$, Terence G. Langdon ${ }^{b, c}$ \\ ${ }^{a}$ Department of Materials Engineering and Civil Construction, Universidade Federal de Minas Gerais - \\ UFMG, Belo Horizonte, MG, Brazil \\ ${ }^{b}$ Departments of Aerospace \& Mechanical Engineering and Material Science, University of Southern \\ California, Los Angeles, CA, U.S.A. \\ ${ }^{c}$ Materials Research Group, Faculty of Engineering and the Environment, University of Southampton, \\ Southampton, U.K.
}

Received: May 26, 2016; Accepted: August 11, 2016

\begin{abstract}
High-pressure torsion was used to process grade 2 titanium to 10 turns using different pressures up to a maximum of $8 \mathrm{GPa}$. $\mathrm{X}$ ray diffraction showed that the as-received material and the material processed at pressures of $2 \mathrm{GPa}$ and $4 \mathrm{GPa}$ were single phase but the material processed at $8 \mathrm{GPa}$ contained both the h.c.p. and the simple hexagonal $\omega$-phase. Nanoindentation was used to determine the mechanical behavior and the results show a pronounced increase in hardness due both to the severe plastic deformation processing and to the phase transformation at the highest pressure. A maximum hardness of $\sim 4.7 \mathrm{GPa}$ was attained.
\end{abstract}

Keywords: commercial purity titanium, high-pressure torsion, phase transformation, severe plastic deformation

\section{Introduction}

Titanium and its alloys have great potential for applications in the transportation industries because of their high strength to density ratio which allows the fabrication of structural components with low weight. Also, titanium can be used as a biomaterial due to its high resistance against corrosion and its biocompatibility. In both applications, transportation and medical, it is important to improve the strength of the material in order to satisfy any structural demand. Grain refinement and strain hardening are widely used as methods for improving the strength of metallic materials. These methods are particularly important for biomaterial applications because hardening by alloying may compromise the biocompatibility of the material.

Severe plastic deformation (SPD) ${ }^{1}$ techniques are now recognized as effective processing operations to introduce grain refinement and strain hardening into metallic materials. These techniques have been used to process commercially pure titanium and significant improvements in strength were reported. For example, Equal-Channel Angular Pressing $(\mathrm{ECAP})^{2}$ has been used to process commercial purity (CP) $\mathrm{Ti}$ and the results show that ultrafine-grained structures are developed and the strength is significantly improved ${ }^{3-13}$. In addition, it was shown that SPD processing by ECAP improves the fatigue life of dental implants fabricated from CP-Ti ${ }^{13}$.

However, even finer grain structures and improved strength may be developed in CP-Ti when processing by high-pressure torsion (HPT) $)^{14}$. The large hydrostatic stress developed during this processing operation prevents cracking

* e-mail: figueiredo@demc.ufmg.br and permits processing at room temperature. Thus grain sizes in the range of a few hundreds of nanometers have been reported in CP-Ti processed by $\mathrm{HPT}^{15-21}$. Also, titanium exhibits a phase transformation at high pressures into an hexagonal $\omega$-phase ${ }^{22,23}$. It was reported that the $\omega$-phase is denser despite the less-packed structure and this was attributed to the smaller atomic size ${ }^{22}$. Recent research shows that the $\omega$-phase is formed in CP-Ti processed by HPT ${ }^{16,17,20,21,24}$. The high pressures developed in this process lead to a phase transformation and the imposed torsional strain stabilizes the hexagonal phase upon pressure release. It is known that the $\alpha$ to $\omega$ phase transition is favored with decreasing oxygen content in the alloy ${ }^{16}$, with increasing pressure ${ }^{17}$, with increasing the numbers of turns in HPT $^{16,17,20,21}$ and with decreasing the rotation rate ${ }^{21}$. However, although the phase transformation has been reported at pressures as low as $5 \mathrm{GPa}$ in $\mathrm{Ti}-0.05 \% \mathrm{O}^{16}$ and in grade $2 \mathrm{Ti}^{21}$, the $\omega$-phase was not detected in CP-Ti of similar grade even after processing by HPT using a pressure of $6 \mathrm{GPa}$ for up to 10 turns $^{19}$. This was attributed to the presence of different amounts of impurities compared to other investigations. It has been reported that larger pressures are needed for transformation in samples with higher impurity contents ${ }^{23}$.

To date, most reports describe the processing of titanium up to a maximum pressure of $6 \mathrm{GPa}$ in HPT. Thus, the objective of the present study was to evaluate the formation of the $\omega$-phase in grade $2 \mathrm{CP}$-Ti processed by HPT at a higher pressure of $8 \mathrm{GPa}$. In addition, nanoindentation was used to evaluate the distribution of hardness and the strain rate sensitivity of the processed material. 


\section{Experimental Material and Procedures}

The material used in the present experiments was a CP-Ti of grade 2 ( $99.5 \%$ purity) provided by Global Metal Trading (UK) Ltd. (Birmingham, U.K.). The material was received as rods with $10 \mathrm{~mm}$ diameter. Discs with $0.9 \mathrm{~mm}$ thickness were cut from the as-received rods using spark erosion and these discs were ground using paper grids to a final thickness of $\sim 0.8 \mathrm{~mm}$.

The material was processed by HPT using a quasi-constrained facility ${ }^{25,26}$ in which each anvil contains a shallow circular depression of $\sim 0.25 \mathrm{~mm}$ depth and $\sim 10 \mathrm{~mm}$ diameter. The discs were placed inside the depression in the bottom anvil for processing. The compression load in the HPT equipment was varied in order to provide different levels of nominal stresses during the processing operation. Thus, samples were processed by 10 turns of HPT using the different pressures of 2, 4 and $8 \mathrm{GPa}$. The samples were processed at $1 \mathrm{rpm}$ $(\sim 0.1 \mathrm{rad} / \mathrm{s})$ and, by considering a flow stress of $1000 \mathrm{MPa}$ (= hardness/3), it was anticipated that the temperature rise on the sample during the HPT processing is $\sim 50{ }^{\circ} \mathrm{C} 27,28$.

Samples of the as-received and the HPT-processed material were embedded in resin, ground and polished to a mirror-like finish on the upper circular surface. The phase constituents of the samples were determined by $\mathrm{X}$-ray diffraction analysis with $\mathrm{Cu}(\mathrm{K} \alpha)$ radiation using a scanning rate of $0.02 \mathrm{rad} / \mathrm{s}$ and $10^{\circ}<2 \theta<120^{\circ}$. Nanoindentation measurements were carried out using a NanoTest Platform 2 nanoindenter (Micro Materials Ltd., Wrexham, UK). A maximum load of $200 \mathrm{mN}$ and dwell time of $30 \mathrm{~s}$ were used in the tests. The loading rate was varied between $1 \mathrm{mN} / \mathrm{s}$ and $5 \mathrm{mN} / \mathrm{s}$ to estimate the material strain rate sensitivity. Clusters of 10 indentations were used to determine the average hardness at selected positions on the processed samples.

\section{Experimental Results and Discussion}

The X-ray diffraction patterns of the material before and after processing by HPT at different pressures are shown in Figure 1. The peaks observed in the unprocessed material correspond to the h.c.p. $\alpha$-phase and also in the material processed by HPT under pressures of 2 and $4 \mathrm{GPa}$. The $\alpha$-phase is also present in the material processed under a pressure of $8 \mathrm{GPa}$ but additional peaks are present in the diffraction pattern and these correspond to the hexagonal $\omega$-phase. Thus, the material processed under the largest pressure exhibits both crystalline structures. This result agrees with earlier reports as $\omega$-phase formation and stabilization was reported after HPT processing at pressures of $5 \mathrm{GPa}$ and larger and after multiple turns ${ }^{16,17,20,21,24}$. On the other hand, no phase transformation was observed in a similar material after HPT processing up to 10 turns at $6 \mathrm{GPa}$ of pressure which suggested higher impurity content in the material ${ }^{19}$. Therefore, the present results show that a higher HPT pressure of $8 \mathrm{GPa}$ favors a phase transformation in this material.

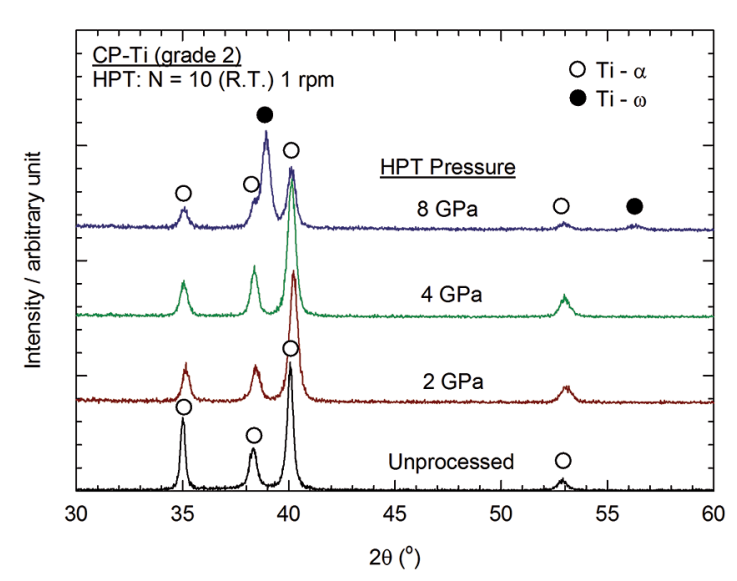

Figure 1: $\mathrm{X}$ ray diffraction patterns for the material before and after processing by HPT.

Figure 2 shows representative load vs. depth curves obtained from nanoindentation in the material before and after HPT processing. The indentations were carried out at the mid-radius position of the discs processed under different levels of pressure. There is a clear tendency of decreasing the depth at peak load in the material processed by HPT and this effect is more pronounced in the material processed at $8 \mathrm{GPa}$. It is also noted that the variation in depth during the $30 \mathrm{~s}$ period at peak load is larger in the unprocessed material which suggests a higher strain rate sensitivity in this condition.

The hardness was determined at different locations of the processed discs and the average values are plotted as a function of the distance from the center in Figure 3: the hardness of the unprocessed material is also shown as a dashed line for comparison. The data show that HPT processing under pressures of 2 and $4 \mathrm{GPa}$ increase the hardness to values between $3.55-3.87 \mathrm{GPa}$ and the distribution is fairly homogeneous throughout each disc. Processing under a larger hydrostatic pressure of $8 \mathrm{GPa}$ leads to an increased hardness in the range of $4.10-4.71 \mathrm{GPa}$ but the distribution is slightly less homogeneous. Specifically, lower hardness values are observed near the center and at the edge of the disc while the mid-radius is harder. The significant increase in hardness in the material processed under the maximum pressure is attributed to the formation of the $\omega$-phase and this is in agreement with other reports. For example, a saturation hardness of $\sim 2.6 \mathrm{GPa}$ was observed in Ti processed at $2 \mathrm{GPa}$ without a phase transformation while a saturation hardness of $\sim 3.4 \mathrm{GPa}$ was observed in the same material processed at $6 \mathrm{GPa}$ which exhibited $\omega$-phase formation ${ }^{17}$.

The hardnesses near the center and at the edge of the disc of the material processed at $8 \mathrm{GPa}$ are lower than at the mid-radius position but nevertheless they are higher than observed in the material processed at lower pressures. This suggests these areas may have experienced lower amounts of phase transformation. The area near the center of the disc is subjected to a lower shear strain and it is known that the $\omega$-phase requires high plastic deformation to prevent 


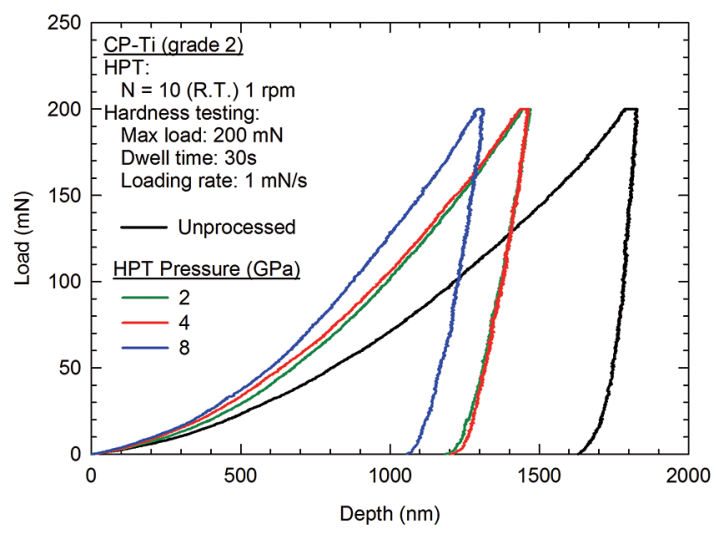

Figure 2: Load vs depth curves for the material before and after processing by HPT using different pressures.

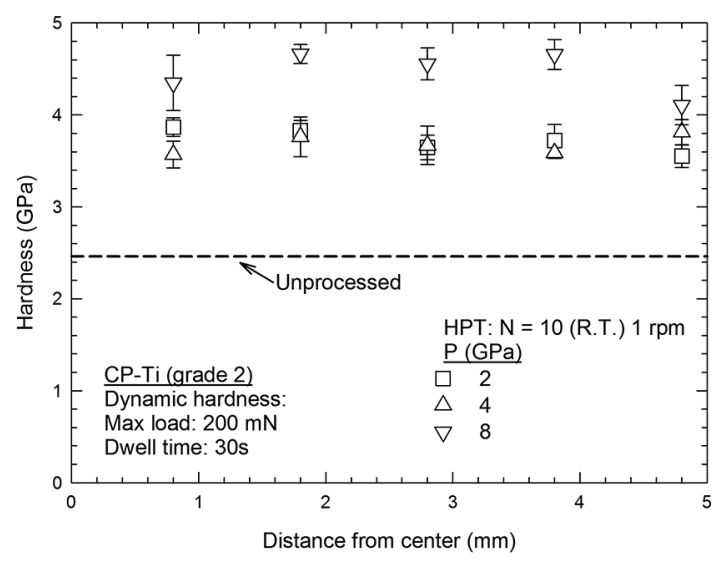

Figure 3: Hardness distribution on discs processed by HPT using different pressures.

any reverse transformation during unloading. This is in agreement with experimental evidence of an increasing volume fraction of $\omega$-phase with increasing imposed strain during $\mathrm{HPT}^{16,17,20,24}$ and a lower hardness distribution near the center of the disc even after 10 turns of HPT ${ }^{16,17,20}$. By contrast, the edge of the disc undergoes maximum plastic deformation and the reduced volume of $\omega$-phase in this case is attributed to a lower hydrostatic stress. Thus, although the disc is subjected to a compressive load through the massive anvils in the HPT facility, finite element modeling has shown that the distribution of hydrostatic stress is not homogeneous and is larger near the center and lower near the edge $^{25}$. Thus, the edge of the disc may be processed under a lower pressure and this effectively reduces the amount of the phase transformation. This is in agreement with the reduced volume fraction of the $\omega$-phase detected by synchrotron characterization at the edges of discs ${ }^{24}$.

Nanoindentation tests were also carried out using different loading rates. An early report showed that the strain rate, $\dot{\varepsilon}$, during hardness testing is given by $\dot{\varepsilon}=1 / h$ $(d h / d t)$ where $h$ is the displacement of the indenter and $t$ is the time, and it is possible to estimate the strain rate sensitivity of the material by comparing its response at different loading rates ${ }^{29}$. Figure 4 shows representative curves for tests in the unprocessed material and the material processed at $8 \mathrm{GPa}$. Figure 4(a) shows the evolution of displacement as a function of time and it is possible to estimate the strain rate during the test. The strain rate variation was found to be proportional to the loading rate change. Figure 4(b) shows the load vs displacement curves and it confirms that the unprocessed material exhibits a different response to the different loading rates while the material processed by HPT at $8 \mathrm{GPa}$ is essentially rate-insensitive. Calculations showed that the strain rate sensitivity in the unprocessed material is $\sim 0.03$ whereas it is $\sim 0.0$ in the material processed by HPT under all testing conditions. The strain rate sensitivity of the unprocessed material agrees with reports for pure titanium ${ }^{30,31}$ although a slight lower value of 0.020 was also reported ${ }^{32}$. On the other hand, the lower values determined for the material processed by HPT differs from the trend of increasing strain rate sensitivity with refining grain structure which was reported elsewhere ${ }^{31}$.
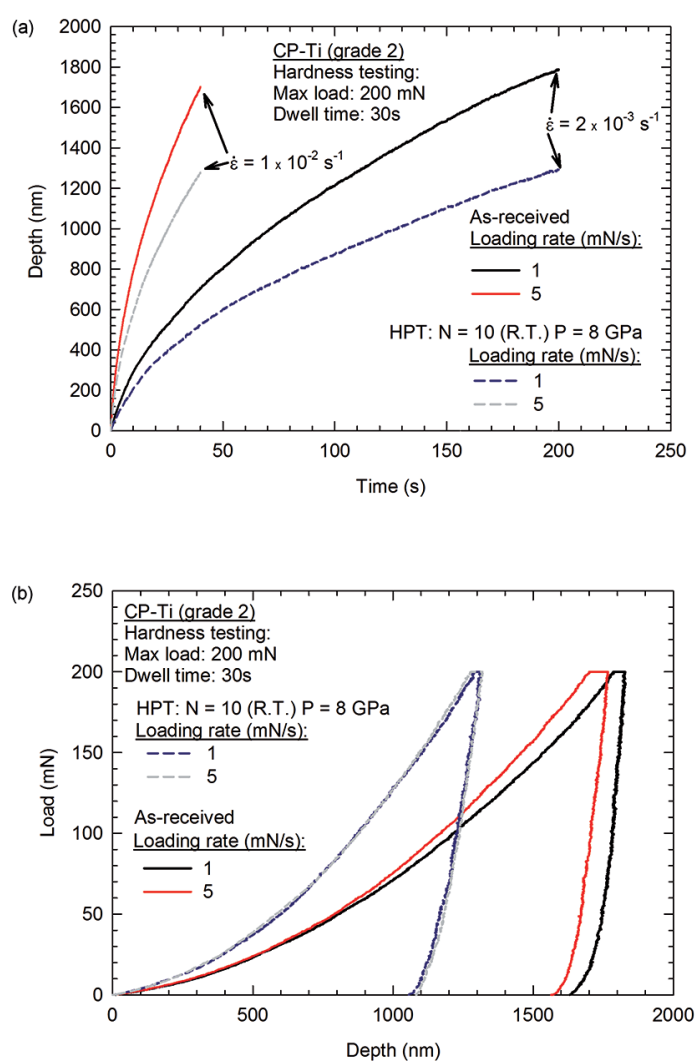

Figure 4: (a) Depth vs Time curves and (b) Load vs depth curves at different loading rates for the unprocessed material and the material processed by HPT at $8 \mathrm{GPa}$. 
Table 1: Summary of data on hardness and development of $\omega$ phase in pure titanium processed by HPT $16,17,19-21,24$.

\begin{tabular}{|c|c|c|c|c|c|c|}
\hline $\begin{array}{l}\text { Oxygen content } \\
(\%)\end{array}$ & $\begin{array}{l}\text { HPT Pressure } \\
(\mathrm{GPa})\end{array}$ & $\begin{array}{l}\text { Number of turns } \\
\text { of HPT }\end{array}$ & $\begin{array}{l}\text { Rotation rate } \\
\quad(\mathrm{rpm})\end{array}$ & $\omega$ phase & $\begin{array}{c}\text { Maximum } \\
\text { hardness }(\mathrm{GPa})\end{array}$ & Reference \\
\hline 0.05 & 1.5 & 5 & 0.2 & no & $\sim 2.5$ & Todaka et al. 2008 \\
\hline 0.05 & 5 & 5 & 0.2 & yes & $\sim 3.7$ & Todaka et al. 2008 \\
\hline 0.2 & 2 & 10 & 0.5 & no & $\sim 2.6$ & Edalati et al. 2009 \\
\hline 0.2 & 6 & 10 & 0.5 & yes & $\sim 3.4$ & Edalati et al. 2009 \\
\hline 0.2 & 40 & 5 & 0.5 & yes & $\sim 4.0$ & Edalati et al. 2009 \\
\hline$<0.25$ & 6 & 10 & 1 & no & $\sim 3.0$ & Wang et al. 2014 \\
\hline$<0.25$ & 6 & $1 / 4$ & 1 & yes & $\sim 2.9$ & Shirooyeh et al. 2014 \\
\hline$<0.25$ & 6 & 10 & 1 & yes & $\sim 3.9$ & Shirooyeh et al. 2014 \\
\hline$<0.25$ & 6 & 5 & 1 & yes & $\sim 4.1$ & Bolmaro et al. 2014 \\
\hline$<0.25$ & 5 & 10 & 0.5 & yes & $\sim 3.6$ & $\begin{array}{l}\text { Shahmir and Langdon } \\
2016\end{array}$ \\
\hline$<0.25$ & 5 & 10 & 1 & yes & $\sim 3.0$ & $\begin{array}{l}\text { Shahmir and Langdon } \\
2016\end{array}$ \\
\hline$<0.25$ & 4 & 10 & 1 & no & $\sim 3.7$ & Present work \\
\hline$<0.25$ & 8 & 10 & 1 & yes & $\sim 4.7$ & Present work \\
\hline
\end{tabular}

The development of the $\omega$-phase and increase in hardness during HPT processing at large pressures for pure titanium has been reported in several investigations and Table 1 shows a summary of the available data. It is apparent that a phase transformation is readily observed after HPT processing of high purity Ti and at pressures larger than $4 \mathrm{GPa}$. Thus, the present results agree with the available reports since the phase transformation was observed only at the highest pressure of $8 \mathrm{GPa}$.

Comparing similar materials processed at the same rotation rate and the same number of turns of HPT, the hardness increases significantly in materials exhibiting an $\omega$-phase due to processing at higher pressures. This confirms the effectiveness of enhancing the hardness of titanium through a phase transformation. There is also a trend of increasing the hardness of the processed material with increasing processing pressure even after reaching the threshold pressure for $\omega$-phase formation. For example, $\omega$-phase formation was reported in samples processed at $6 \mathrm{GPa}$ but the hardness of the processed material increased with increasing processing pressure up to $40 \mathrm{GPa}^{17}$. Thus, the present results show a higher hardness of $\sim 4.7 \mathrm{GPa}$ in titanium in Figure 3 and this higher value is attributed to increased impurities and to the higher processing pressure.

\section{Summary and Conclusions}

1. Commercial purity titanium of grade 2 was processed by 10 turns of HPT at pressures of 2, 4 and $8 \mathrm{GPa}$. X ray diffraction revealed the presence of an $\omega$-phase in the material processed at the highest pressure.
2. Nanoindentation revealed a pronounced increase in hardness due to HPT processing and this effect was even more pronounced in the material processed at $8 \mathrm{GPa}$ of pressure due to the phase transformation which gave a maximum hardness of $\sim 4.7 \mathrm{GPa}$.

3. The distribution of hardness in the material processed at $8 \mathrm{GPa}$ was heterogeneous with higher values at the midradius position and lower values near the center and at the edge of the disc. These lower values were attributed to the reduced $\omega$-phase content due to the low shear strain near the center of the disc and the reduced pressure at the edge.

4. Nanoindentation tests with different loading rates showed that HPT processing reduced the strain rate sensitivity of titanium essentially to 0 .

\section{Acknowledgements}

This work was supported by FAPEMIG and CNPq in Brazil and by the European Research Council under ERC Grant Agreement No. 267464-SPDMETALS.

\section{References}

1. Valiev RZ, Islamgaliev RK, Alexandrov IV. Bulk nanostructured materials from severe plastic deformation. Progress in Materials Science. 2000;45(2):103-189.

2. Valiev RZ, Langdon TG. Principles of equal-channel angular pressing as a processing tool for grain refinement. Progress in Materials Science. 2006;51(7):881-981.

3. Stolyarov VV, Zhu YT, Lowe TC, Valiev RZ. Microstructure and properties of pure Ti processed by ECAP and cold extrusion. Materials Science and Engineering: A. 2001;303(1-2):82-89. 
4. Zhao X, Fu W, Yang X, Langdon TG. Microstructure and properties of pure titanium processed by equal-channel angular pressing at room temperature. Scripta Materialia. 2008;59(5):542-545.

5. Valiev RZ, Semenova IP, Latysh VV, Rack H, Lowe TC, Petruzelka $\mathrm{J}$, et al. Nanostructured titanium for biomedical applications. Advanced Engineering Materials. 2008;10(8):B15-B17.

6. Stolyarov VV, Zeipper L, Mingler B, Zehetbauer M. Influence of postdeformation on CP-Ti processed by equal channel angular pressing. Materials Science and Engineering A. 2008;476(1-2):98-105.

7. Purcek G, Saray O, Kul O, Karaman I, Yapici GG, Haouaoui M, et al. Mechanical and wear properties of ultrafine-grained pure Ti produced by multi-pass equal-channel angular extrusion. Materials Science and Engineering A. 2009;517(1-2):97-104.

8. Kang DH, Kim TW. Mechanical behavior and microstructural evolution of commercially pure titanium in enhanced multi-pass equal channel angular pressing and cold extrusion. Materials \& Design. 2010;31(Suppl 1):S54-S60.

9. Zhao X, Yang X, Liu X, Wang X, Langdon TG. The processing of pure titanium through multiple passes of ECAP at room temperature. Materials Science and Engineering: A. 2010;527(23):6335-6339.

10. Zhang Y, Figueiredo RB, Alhajeri SN, Wang JT, Gao N, Langdon TG. Structure and mechanical properties of commercial purity titanium processed by ECAP at room temperature. Materials Science and Engineering: A. 2011;528(25-26):7708-7714.

11. Zhang Y, Alhajeri SN, Figueiredo RB, Gao N, Wang JT, Langdon TG. Contribution of Twins to the Strengthening of Commercial Purity Titanium after Equal-Channel Angular Pressing. Materials Science Forum. 2010;667-669:719-724

12. Sordi VL, Ferrante M, Kawasaki M, Langdon TG. Microstructure and tensile strength of grade 2 titanium processed by equalchannel angular pressing and by rolling. Journal of Materials Science. 2012;47(22):7870-7876.

13. Figueiredo RB, Barbosa ERC, Zhao X, Yang X, Liu X, Cetlin PR, et al. Improving the fatigue behavior of dental implants through processing commercial purity titanium by equal-channel angular pressing. Materials Science and Engineering: A . 2014;619:312-318.

14. Zhilyaev AP, Langdon TG. Using high-pressure torsion for metal processing: Fundamentals and applications. Progress in Materials Science. 2008;53(6):893-979.

15. Islamgaliev RK, Kazyhanov VU, Shestakova LO, Sharafutdinov AV, Valiev RZ. Microstructure and mechanical properties of titanium (Grade 4) processed by high-pressure torsion. Materials Science and Engineering: A. 2008;493(1-2):190-194.

16. Todaka Y, Sasaki J, Moto T, Umemoto M. Bulk submicrocrystalline $\omega$-Ti produced by high-pressure torsion straining. Scripta Materialia. 2008;59(6):615-618.

17. Edalati K, Matsubara E, Horita Z. Processing Pure Ti by HighPressure Torsion in Wide Ranges of Pressures and Strain. Metallurgical and Materials Transactions A . 2009;40(9):2079-2086.

18. Wang CT, Gao N, Gee MG, Wood RJK, Langdon TG. Processing of an ultrafine-grained titanium by high-pressure torsion: An evaluation of the wear properties with and without a TiN coating. Journal of the Mechanical Behavior of Biomedical Materials. 2013;17:166-175.
19. Wang CT, Fox AG, Langdon TG. An Investigation of Hardness Homogeneity and Microstructure in Pure Titanium Processed by High Pressure Torsion. Materials Science Forum. 2014;783-786:2701-2706.

20. Shirooyeh M, Xu J, Langdon TG. Microhardness evolution and mechanical characteristics of commercial purity titanium processed by high-pressure torsion. Materials Science and Engineering: A. 2014;614:223-231.

21. Shamir H, Langdon TG. Characteristics of the allotropic phase transformation in titanium processed by high-pressure torsion using different rotation speeds. Materials Science and Engineering: A. 2016;667:293-299.

22. Jamieson JC. Crystal Structures of Titanium, Zirconium, and Hafnium at High Pressures. Science. 1963;140(3562):72-73.

23. Vohra YK, Sikka SK, Vaidya SN, Chidambaram R. Impurity effects and reaction kinetics of the pressure-induced $\alpha \rightarrow \omega$ transformation in Ti. Journal of Physics and Chemistry of Solids. 1977;38(1):1293-1296.

24. Bolmaro RE, Sordi VL, Ferrante M, Brokmeier HG, Kawasaki M, Langdon TG. High-Pressure Torsion of Ti: Synchrotron characterization of phase volume fraction and domain sizes. IOP Conference Series: Materials Science and Engineering. 2014;63:012147.

25. Figueiredo RB, Cetlin PR, Langdon TG. Using finite element modeling to examine the flow processes in quasi-constrained high-pressure torsion. Materials Science and Engineering: A. 2011;528(28):8198-8204.

26. Pereira PHR, Figueiredo RB, Cetlin PR, Langdon TG. Using finite element modeling to examine the flow process and temperature evolution in HPT under different constraining conditions. IOP Conference Series: Materials Science and Engineering. 2014;63:012041.

27. Figueiredo RB, Pereira PHR, Aguilar MTP, Cetlin PR, Langdon TG. Using finite element modeling to examine the temperature distribution in quasi-constrained high-pressure torsion. Acta Materialia. 2012;60(6-7):3190-3198.

28. Pereira PHR, Figueiredo RB, Huang Y, Cetlin PR, Langdon TG. Modeling the temperature rise in high-pressure torsion. Materials Science and Engineering: A. 2014;593:185-188.

29. Mayo MJ, Nix WD. A micro-indentation study of superplasticity in $\mathrm{Pb}, \mathrm{Sn}$, and $\mathrm{Sn}-38 \mathrm{wt} \% \mathrm{~Pb}$. Acta Metallurgica. 1988;36(8):2183-2192.

30. Peykov D, Martin E, Chromik RR, Gauvin R, Trudeau M. Evaluation of strain rate sensitivity by constant load nanoindentation. Journal of Materials Science. 2012;47(20):7189-7200.

31. Hajizadeh K, Eghbali B, Topolski K, Kurzydlowski KJ. Ultrafine grained bulk CP-Ti processed by multi-pass ECAP at warm deformation region. Materials Chemistry and Physics. 2014; 143(3):1032-1038.

32. Semiatin SL, DeLo DP. Equal channel angular extrusion of difficult-to-work alloys. Materials \& Design. 2000;21(4):311-322. 